AperTO - Archivio Istituzionale Open Access dell'Università di Torino

\title{
Leaving Mum Alone? The Effect of Parental Separation on Children's Decisions to Leave Home
}

\section{This is the author's manuscript}

Original Citation:

Availability:

This version is available http://hdl.handle.net/2318/121414

since

Terms of use:

Open Access

Anyone can freely access the full text of works made available as "Open Access". Works made available under a Creative Commons license can be used according to the terms and conditions of said license. Use of all other works requires consent of the right holder (author or publisher) if not exempted from copyright protection by the applicable law. 


\section{(2) \\ UNIVERSITÀ DEGLI STUDI DI TORINO}

This is an author version of the contribution published on:

Leaving Mum Alone? The Effect of Parental Separation on Children's Decisions to Leave Home

(L. Mencarini, E. Meroni, C. Pronzato)

European Journal of Population (2012) 28:337-357

(DOI 10.1007/s10680-012-9267-0)

The definitive version is available at:

http://link.springer.com/article/10.1007\%2Fs10680-012-9267-0 


\title{
Leaving mum alone? \\ The effect of parental divorce on children's leaving home decisions
}

\author{
Letizia Mencarini \\ University of Turin, Collegio Carlo Alberto and CHILD \\ letizia.mencarini@unito.it \\ Elena Meroni \\ Department of Statistical Sciences, University of Padua and \\ Dondena Centre, Bocconi University \\ elena.meroni@stat.unipd.it \\ Chiara Pronzato \\ Dondena Centre, Bocconi University, Collegio Carlo Alberto \& CHILD \\ chiara.pronzato@unibocconi.it
}

\begin{abstract}
There is a growing literature considering the relationship between parental divorce and children's life-course patterns. However, there is no general consensus on whether parental separation accelerates or postpones children's transition to adulthood. The aim of this paper is to add to this literature by analyzing the effect of parental divorce on the timing of nestleaving of young adults. After providing descriptive findings using the recent Generations and Gender Survey (GGS) for five European countries (France, Georgia, Hungary, Italy, Russia), we assess the extent to which the associations between divorce and nest-leaving timing is masked by different effects. First, do children of divorced parents develop different characteristics (e.g., human capital construction and socialization) which in turn make them leave the parental home at a different rate? Secondly, do children of divorced people leave the parental home at a different age because of the new family structure? Our findings show that children who experienced divorce leave home at a faster rate, but the last child in the household - who would leave the mother alone - delays his/her departure.
\end{abstract}

\section{Keywords:}

Generations and Gender Survey, GGS, divorce, living home, life-course patterns, France, Georgia, Hungary, Italy, Russia 


\section{Introduction}

There is a growing literature considering the relationship between parental divorce and children's life-course patterns. Nevertheless in the wider literature on consequences of marital dissolution for children, only few studies devote attention to the role that family structure altered as a consequence of family disruption - plays in the propensity for a young adult to leave home. And more generally, there is no clear consensus on whether parental separation accelerates or postpones the children's transition to adulthood.

There are huge variations in the average age at which young adults leave the parental home within and across European countries (Billari et al., 2001; Billari and Liefbroer, 2010; Corijn and Klijzing, 2001). At the same time, divorce rates are increasing across all of Europe, including those countries where divorce and separation have traditionally been low, hence it becomes very important to try to provide insights on how growing up in a divorced family may affect the way young people decide how long to live with their parents and how this effect varies across different countries. No doubt, the experience of divorce will be more commonplace for young adults in the future. Among European children, divorce has already replaced death as the main cause of family disruption and rising divorce rates have led to an increase in the proportion of children who have experienced the breakup of their parents' marriages. Research has only recently begun to explore the implications of these trends for the lives of the children involved, but the vast number of children so affected underscores the importance of these issues.

Focusing just on determinants of different timing at nest-leaving for children of disruptive families, researchers have indicated both direct and indirect effects. The former are those resulting from the changes in family structure that produces incentives or disincentives to leave home; while the latter are those referring to children's cognitive and non-cognitive skill formation due to the fact of being grown up in a disruptive family during childhood.

The literature has raised several hypotheses where parents' separation may have both direct and indirect effects on children's transition to adulthood. Our analysis contributes to this relatively large literature, in particular focusing on the leaving home process, with the specific aim to disentangle different effects that parental divorce can have on the timing of homeleaving. In this framework, we try to assess the extent to which the overall association between divorce and leaving home is masked by various effects. More precisely, the aim is to try to answer to the following questions: first, do children of divorced parents develop different characteristics (for example, their human capital construction and their socialization) that in turn make them leave the parental home at a different rate? Secondly: do children of divorced parents leave the parental home at a different age also because of the new family structure, that is the mother would be alone at home if they leave? Thirdly: do children of divorced parents have different unobservable characteristics, which would make them, in any case, leave the parental home at a different rate?

The fact that the phenomenon of divorce is in a rapid increase in most families in traditional European countries (such as the Southern and some Eastern ones) gives not only new interest on the link with child outcomes, but also contributes to provide social scientists with a sufficient number of survey sample cases to implement empirical analysis. Here, we take advantage of the availability of longitudinal retrospective family history data from the recent Generations and Gender Surveys (GGS) to test our hypotheses on the different contexts of five European countries (France, Georgia, Hungary, Italy, and Russia). As for methodology, 
we study nest-leaving by means of discrete duration models (complementary log-log specification with random effects at household level), running separate regressions for each country.

\section{The theoretical perspectives on parental divorce and leaving home}

The hypothesis that parental divorce affects the time when young adults decide to leave home has been tested empirically, especially in the North American context (McLanahan, 1985, 1988; McLanahan and Bumpass, 1988; McLanahan and Garfinkel, 1989; Astone and McLanahan, 1994; McLanahan and Sandefur, 1994; McLanahan and Percheski, 2008) but much less in the European one (apart from O'Connor et al., 2003; Bernhardt et al., 2005; Ongaro and Mazzuco, 2009). These studies show that individuals coming from dissolved families leave home earlier than individuals from intact families. This result is quite robust (Aquilino, 1991; Tang, 1997; Kiernan, 1997; Goldscheider and Goldscheider, 1988, 1998, 1999; Bernhardt et al., 2005), although it should be seen in the context of specific patterns of both transition to adulthood and family dissolution, since it mainly refers to North American or Northern European countries, where divorce is widely diffused and the transition out of the parental home tends to take place anyway at a relatively early ages. The broader hypothesis, that experiencing parental separation can influence directly or indirectly the events of children's transition out of the parental home, is embedded in the wider literature on the general effects that parental divorce has on children's development, on their transition to adulthood and on their subsequent life-course patterns.

It seems beyond doubt that parental divorce is associated with a worsening of children's outcomes (Steele et al., 2009). The majority of studies show that children of divorced couples are more likely to exhibit psychological, behavioral, social and school problems than children raised in continuously intact two-parent families. Further studies also suggest that this gap persists well into adulthood (Amato et al., 1995). The general evidence is that children from dissolved families are more often long-term depressed (O'Connor et al., 2003); complete fewer years of school and are more likely to drop out of school (Astone and McLanahan, 1994); have different attitudes towards sexuality, divorce and family formation (Kiernan, 1997; Amato and Booth, 1991; Amato and DeBoer, 2001; Aquilino, 1994; Axinn and Thornton, 1996; Furstenberg and Teitler, 1994; Thornton, 1991; Both and Amato, 1994; Ongaro and Mazzuco, 2009); start sexual activity earlier, start family and have children at younger ages (Kiernan, 1997; McLahan and Sanderfur ,1994), are more likely to cohabit (Furstenberg and Teitler, 1994) and to experience marital disruption themselves (Cherlin et al., 1995; Teachman, 2002). Despite divorce having become more commonplace, and the lowering of the social stigma associated to it, the negative association has not declined over the time and the average child of a divorced family is ubiquitously confirmed as coming from a trouble family (Steele et al., 2009).

Moreover, the negative association between parental divorce and poor child outcomes could be due, in part, to different unobservable characteristics which affect both divorce and child outcomes at the same time. There might be a "selection effect", i.e. children of divorced people (as well as their parents) have different characteristics compared to those of intact families. Therefore, a number of features and behaviors of children of divorced parents do not derive from the disruption itself, but from previous differential characteristics in background. Kiernan (1997) sustained, for instance, that children who grow up with both biological 
parents may end up better off both educationally and economically largely because they were advantaged to begin with, not necessarily because their parents stayed together. Moreover, from several other studies (Cherlin et al., 1991; Aughinbaugh, 2005) there is evidence of powerful selection effects operating particularly through family hardship, so that the effect of family disruption disappears when controlling for pre-divorce circumstances, including background socio-economic characteristics of the family. The significance of selection seems, however, weaker when the outcome refers to a demographic behavior, such as leaving home.

Early partnership and parenthood are more common among the young adults whose parents divorced whilst they were children. The robustness of these findings across time and space suggests that these outcomes may well be directly linked to parental divorce in childhood.

When we refer to indirect consequences of divorce of the parents, we mean that children growing up in disrupted families may develop different characteristics, which are linked to different modalities and timing of the leaving home process (Cherlin et al., 1995). As a result of divorce, the family where the child continues to live - often a female-headed, single-parent family - tends to be poorer (Aassve et al., 2007 and 2009) and usually most of the effects of single parenthood are caused by the economic circumstances of single mothers. The impact of childhood family structure and the negative effects of family disruption on children's educational and occupational attainment are not due to father-absence per se, but to the economic deprivation and family stress that accompany a change in family structure (McLanahan, 1985). There is good evidence that family socio-economic status also mediates some of the longer-term influences of family structure on adult functioning.

Economic deprivation plays an important role in the transmission of problems from singleparent families to the next generation. Poorer families may have less money to spend on educational activities and less time available to help children with schoolwork. Economic conditions and educational outcomes are among the main determinants of the nest-leaving process, although the effects are contradictory. Shorter educational paths and fewer resources from the family can accelerate the process of independent life and leaving home, in order to find better conditions outside the family. On the other hand, lower education and resources are also linked to the higher likelihood to be unemployed or to find less well paid and less stable work and can result in the lack of resources to exit the parental home.

Even more important than the economic conditions, though, is the parent-child relationship. Parental conflict, as well as the absence of one parent, interferes with the child's attachment to the parents, making it more difficult to transmit values. Research has shown that children from high conflict families - regardless of whether their parents divorce or not - perform, in any case, worse at school (Cummings and Davies, 1994). Furthermore, there is more often weaker parental control over the behavior of the children, because for instance single mothers are less authoritative and less effective disciplinarians, leading to the fact that children (especially females) who spend part of their childhood in one-parent families are more likely to have an earlier sexual debut, and then marry and bear children earlier.

According to McLanahan and Bumpass (1988) all these results support the so-called "socialization explanation", which argues that parental role models and parental supervision are the major factors in determining the offspring's future family formation behavior (more than the hypothesis of socialization and stress), and the "role-model explanation", which argues that children develop their own ideas of what is acceptable and "workable" behavior from what they observe in their parents. Therefore, the extent to which differential outcomes 
are associated with children's characteristics and their living arrangements are mediated by parents' attitudes and behavior (Musick and Bumpass, 1999).

The direct effects, acting as push factors on leaving home, are linked to the family structure (Aquilino, 1991; Mitchell, 1994). After divorce, the child usually reduces the quantity and quality of contact with the non-co-resident parent, and in many cases is forced to live in a new step-family. Some studies advocate that children who live with a step-parent for some time during childhood will leave home sooner than children who live with biological parents (and the effect is stronger for girls than for boys). (Aquilino, 1991; Holdsworth, 2000). The effect is usually reinforced by the presence of half- or step-siblings, who weaken parent-child bonds in step-families. As a result, children in step-families leave the nest sooner than children who live with both biological parents. The step-family effect on home-leaving is typically attributed to more problematic parent-child relationships in remarried households.

Conversely, home-leaving in single-parent families has received less attention than in stepfamilies. Youths exposed to a single-parent family environment are more likely to remain at home than those exposed to a step-family structure, although both categories (those living in a post-divorce single-parent family and in a step-family) leave the nest sooner than children who live with both biological parents. This is heavily linked to the fact that young adults living in both step-parent and single-parent families are more likely to have conflictual parentchild relations. As for the effect of parental divorce by gender, the pattern of interaction suggests that variations in childhood family structure exerts a greater influence on girls' than on boys' home leaving patterns, but the results are contradictory. Bernahrdt et al. (2005) found, for instance, that whereas family conflict seems to have a larger impact on the nestleaving pattern for women, living with a step-parent seems to be more important for men. Aquilino (1991) found that girls with a step-parent or step-siblings were more likely to establish early residential independence than girls from intact families, and this was not true for boys. Nevertheless, studies in this area have not considered a full range of living situations, for instance the fact of living at home with a single-parent with or without siblings. In general the presence of siblings at home (also if not half- or step-siblings) is always linked with a higher youth mobility and earlier nest-leaving (Rainer and Siedler, 2009).

\section{Methodological approach, strategy of analysis and research hypotheses}

Building on previous research, we hypothesize that the leaving home decision depends on parental divorce and other characteristics of the young person and his or her family.

$$
\text { Leave home }=\mathrm{f}(\text { divorce; other characteristics })
$$

This relationship captures just a gross effect of being a child of divorced parents, without telling much about why and what leads to certain behaviors in the leaving home process. Indeed we believe that the effect of parental divorce on nest-leaving timing works through different channels and at different points in time. At the time the parental divorce takes place, children face a change which may influence their development and this will eventually affect their decision to leave home afterwards. We call this the "development effect". The development effect can be thought of as the effect that divorce could have on cognitive and non-cognitive skills that the children will develop during childhood. In most literature and across different contexts, divorce has always been shown to have a negative effect on these skills, but it is not clear whether this leads to leaving the home earlier or later. Indeed children 
of divorced parents are usually less educated and find it harder to achieve stable employment positions, moreover their families are usually poorer and may find it difficult to economically sustain a young adult who wishes to leave the family and set up a new household. Therefore children of divorced parents are often in a relatively more difficult economic situation and this will delay departure from the parental home. On the other hand, since their educational career is on average shorter, they have access to the job market earlier and since they also tend to enter into union earlier, the net effect can be that they leave home at a younger age.

Nevertheless this mechanism could in turn be influenced by contextual factors, such as the generosity of state welfare provision to single-parent families, to young couples or to low wages employee.

On the other hand, later on the life-course, at the time children have to take the decision to leave the parental home, the structure of the family they are living in can influence their choice. We call this the "co-residence" effect.

Children of divorced parents mostly cohabit with the mother and, if there is no step-parent or half/step-siblings in the household, this may act as a disincentive to leave. More specifically, we expect that children living with a lone mother, and with no other siblings at home, leaves the parental home at a slower rate since the cost of leaving is higher, mainly for two reasons. Firstly the lone mother values the child staying at home more positively and the child may feel reluctant to leave the mother home alone; secondly the child may have less incentive to leave since the dwelling is less crowded and therefore there is enough privacy in the parental home and no strict need to leave it to have independence .

Finally, there can be important interaction effects among elements of the family structure. In this framework we believe that the presence of siblings plays an important role, for both the development and the co-residence effects. At time of divorce, a larger family composed of many siblings could mean even more poverty and straitened economic circumstances, which could negatively influence the child's development. On the other hand living in larger family, even after the departure of one the parents, could buffer the negative effects of divorce on children's developing skills, in particular the presence of siblings could in part compensate for damage caused by the lack of one parent.

In the same way, having siblings still living in the home can influence the co-residence effect, which could be mitigated by the presence of other children. With more siblings, the home is more crowded and therefore the child at some point could feel the need to leave to have more privacy and a more independent life. In addition knowing that at least one sibling is still living in the home and therefore the mother is not left alone, could furthermore accelerate the departure from the parental home.

Given these considerations, we might rewrite equation (1) as follows:

Leave home $=\mathrm{f}($ development, co-residence, siblings; other characteristics $)$

In the first step of our empirical analysis, we compare the leaving home decisions of children of divorced and not-divorced parents, by simply including a time-varying dummy variable "divorce" in the following hazard rate equation:

$$
h_{i t}=1-\exp \left[-\exp \left(\alpha+\theta X_{i}+\delta H_{i t}+\beta_{0} D_{i t}+\gamma T\right]\right.
$$


That is, the hazard for child $i$ in year $t$ of leaving the parental home is a function of the characteristics of the child $(X)$, of the household $(H)$, of parental divorce $(D)$ and of the time spent at home after age $17(T)$. We choose a complementary log-log hazard specification, which is consistent with a discrete time model and interval censored survival time data (Jenkins 2005). The hazard is to be interpreted as the conditional probability of leaving the parental home at time $t$, conditional on having stayed at home until time $t-1$.

Young individuals enter the sample when they are at risk of leaving home (here assumed to be from age 18). For each child $i$ in each year $t$ we observe whether he has left the parental home, what is the partnership status of the mother and how many siblings are still living in the same household (plus a set of other time invariant characteristics of the child and of the mother through $X$ and $H$ ). Each child has therefore a "duration", which indicates the time, expressed in years, he or she takes to leave home since age 18 (e.g. if a child leaves home at 21 his or her duration is 3 years). The duration is censored if they have not left home (i.e. still live in the parental home at the time of observation). The main variable of interested is $\mathrm{D}_{i t}$, a time varying dummy which becomes equal to 1 from the year the parents divorce. If a woman has always been a single mother, this dummy's value is always 1 . The variable can take back value 0 if the mother (re-)enters a cohabiting partnership. The coefficient $\beta_{0}$ gives us the gross effect of divorce not yet specified as combination of co-residence and development effects.

To capture these two effects we need a further specification that allows us to estimate the divorce effect interacted with the age of child at divorce and with the possible presence of any sibling both at the time the divorce took place and at the time the child has to decide to leave the home:

$$
h_{i t}=1-\exp \left[-\exp \left(\alpha+\theta X_{i}+\delta H_{i t}+\beta_{1} D_{i t}+\beta_{2} A_{i} D_{i t}+\beta_{3} S_{i} A_{i} D_{i t}+\beta_{4} L_{i t} D_{i t}+\gamma T\right]\right.
$$

The hazard function now depends on the variable, divorce, also through the interaction with other variables: the age of the child when parents divorce, expressed as a dummy variable (A) that takes value 1 if the child was younger than 18 and 0 otherwise; the presence of siblings at the time of divorce $(\mathrm{S})$, again expressed as a dummy that takes value 1 if the child was alone at the time of divorce interacted with the age variable (A); and, finally, the presence of siblings at the time the child leaves the parental home (L), expressed as a dummy variable that takes value 1 if the child was the last (the only) one still living at home. Notice that variables $\mathrm{A}$ and $\mathrm{S}$ are time invariant, while $\mathrm{D}$ and $\mathrm{L}$ can change over time, according the partnership status of the mother and to the presence of other siblings at home.

This specification allows us to capture the development effect which is given by the coefficient $\beta_{2}$ for children who have siblings, while it is equal to the sum of $\beta_{2}$ and $\beta_{3}$ for only children. The reasoning is that children may react differently according to the age they were when parents divorced: if they were still young (younger than 18) divorce may have affected their development, while if they were older, divorce should not have anymore any effect on their skill formation, which happened when their parents were still together.

The co-residence effect is instead captured by coefficient $\beta_{1}$ for children who have at least one sibling still living with the mother at the time they leave the parental home, while it is equal to the sum of $\beta_{1}$ and $\beta_{4}$ for children who are the last child to leave. Therefore, with the above specification, we are able to separate the gross effect of divorce into two specific 
effects, one affecting the child's development at the time the parents divorced and during childhood, and one coming into play only once the child has grown up and can decide whether to leave home.

Nevertheless it is well known that divorce is not a random event: couples (or individuals) selfselect into divorce, and hence all the effects we find could be driven, at least in part, by this selection. In particular, there may be unobservable pre-existing characteristics which influence both the probability that parents divorce and the decision of leaving home. If this were the case we would observe the same differences between children of non-divorced parents and children of divorced parents even in the absence of divorce. We refer to this as the "selection effect". Selection into divorce probably varies across countries, being driven in turn by structural factors such as economic situation and norms concerning divorce. Thus, the impact of divorce on the leaving home process may be very different in countries where divorce is still rare and possibly stigmatized compared to countries where it is more common and accepted by society.

The methodological challenge is then to distinguish empirically the selection effect from the development and the co-residence effects. To solve this issue in the second step of our empirical analysis, we compare the leaving home decisions of children whose parents have been alive and together all along with the leaving home decisions of children who experienced the death of the father. The death event, in the age-range of the considered parents, may be considered much more random than the decision to divorce, and may therefore distinguish the development and co-residence effect estimated by (4) from the selection effect for divorce. We are aware that experiencing a divorce or the death of a parent are two distinct events that may have different effects on the child's behavior and the development effect, nevertheless we argue that when considering the co-residence effect these two events can be compared, since the family structure resulting from both events is similar. Indeed children are in the situation of having more space at home, having more privacy and being concerned with leaving their only remaining parent home alone. Comparing results from children of divorced parents with those from children of widowed mothers could give us an insight about how the selection effect works. We consider therefore a sample of children from intact families, where the father may have died, and include a dummy variable "death" in the following equation:

$$
h_{i t}=1-\exp \left[-\exp \left(\alpha+\theta X_{i}+\delta H_{i t}+\lambda_{0} W_{i t}+\gamma T\right]\right.
$$

The coefficient $\lambda_{0}$ gives us the gross effect of growing and residing with only the mother. The difference between $\beta_{0}$ and $\lambda_{0}$ gives a first suggestion of the selection effect. Similarly, we write the leaving home decision as depending also on the interaction between being the child of a widow and the structure of the family we obtain the following equation:

$$
h_{i t}=1-\exp \left[-\exp \left(\alpha+\theta X_{i}+\delta H_{i t}+\lambda_{1} W_{i t}+\lambda_{2} A_{i} W_{i t}+\lambda_{3} S_{i} A_{i} W_{i t}+\lambda_{4} L_{i t} W_{i t}+\gamma T\right]\right.
$$

All the specified models are estimated controlling for possible random effects at the household level. This is done in order to capture the effect of being born and raised in the same family, since education, development and behavior depend much on the environment children live in, and therefore including these random effects is important to control for possible noise that could otherwise influence our results. 


\section{Data, sample characteristics and the contextual differences}

Our analyses are based on data from recent nationally representative comparative surveys, in the framework of the Gender and Generation Survey (GGS), for five European countries: France, Georgia, Hungary, Italy ${ }^{1}$ and Russia ${ }^{2}$. This is a retrospective survey, where respondents provide information about their fertility, marriage or partnership and work histories. For our analysis we select all respondent women with at least one child older than 18 , since we consider a child at risk of leaving home starting from that age. We have information for all the children of each woman, both those still living in the parental household and those who have already left. Due to the retrospective nature of the survey we are able to reconstruct histories for very old women as well as younger ones, and therefore to study the timing of leaving home for their children who are currently adults ${ }^{3}$. For each child we know whether she or he lefts the parental home and at what age.

We include in our models variables related to the adult-child and his/her mother's characteristics and family composition. The main independent variables of interest for our hypotheses are parental divorce and parental death, which are built as time-varying on a yearly base. They represent the spells lived in single-motherhood (excluding never married single mothers), by mother separated/divorced or widowed without a new cohabiting partner. Most of the other independent variables used in the analyses are those known in the previous literature to influence the timing of nest-leaving: the gender of the child and other household characteristics such as mother's age, level of education, cohort of birth, opinion on leaving home, and whether there are other siblings in the household (i.e. if the child is the last or only child leaving home).

As outlined in the introduction, we employ a discrete duration model (complementary log-log specification with random effects at household level). We run separate regressions for the five countries (Italy, France, Hungary, Russia and Georgia). Descriptive results shown in Table 1 confirm the well-known gender difference at age of leaving home within and across countries: females are always more at risk of leaving than males. Moreover we find a systematic delay at age of leaving home for children of non-intact families (i.e. experiencing a parental separation or divorce, or the death of the father).

Table 2 reports all frequencies, by country, of the variables used in our analyses. These data also provide a first insight into the different contexts characterizing the samples in the different countries. For the analyses that will follow, it has to be noted that the sample size of the different surveys is quite variable with a low number of total cases combined with low frequency of the relevant events. Divorce is not very frequent in Italy and Georgia, which has implications for the estimation.

\footnotetext{
${ }^{1}$ The survey analyzed for Italy is also called "Family and Social Subjects"(FSS).

${ }^{2}$ We used for all countries the first wave of the longitudinal surveys, containing retrospective information.

${ }^{3}$ There are few children who live in the parental home after their marriage (making their spouse move into their parents' home). This was especially the case in Georgia and Hungary, and we decided to drop these individuals from the sample since they probably will never leave their parents' home, given that they have established their own household there.
} 
Table 1: Age at leaving home for children in intact and non-intact families, by sex and country (calculated with Kaplan-Meier survival analysis estimations)

\begin{tabular}{|c|c|c|c|c|c|c|}
\hline & & Italy & France & Hungary & Russia & Georgia \\
\hline \multicolumn{7}{|c|}{ FEMALES } \\
\hline \multirow[t]{2}{*}{ First quartile } & Intact Family & 23 & 19 & 20 & 19 & 20 \\
\hline & Non-intact family & 24 & 19 & 23 & 21 & 21 \\
\hline \multirow[t]{2}{*}{ Median } & Intact Family & 26 & 21 & 23 & 23 & 24 \\
\hline & Non-intact family & 28 & 21 & 25 & 27 & 31 \\
\hline \multicolumn{7}{|c|}{ MALES } \\
\hline \multirow[t]{2}{*}{ First quartile } & Intact Family & 25 & 20 & 22 & 20 & 25 \\
\hline & Non-intact family & 27 & 20 & 24 & 23 & 32 \\
\hline \multirow[t]{2}{*}{ Median } & Intact Family & 28 & 22 & 25 & 24 & 31 \\
\hline & Non-intact family & 33 & 23 & 29 & 30 & $42 *$ \\
\hline
\end{tabular}

Note. * Sample size of children in non-intact families is very small for Georgia and Italy, see Table 2.

Table 2: Descriptive statistics for the survey samples

\begin{tabular}{|c|c|c|c|c|c|}
\hline & Italy & France & Hungary & Russia & Georgia \\
\hline Child is female & $48.2 \%$ & $48.8 \%$ & $48.2 \%$ & $47.8 \%$ & $52.0 \%$ \\
\hline \multirow{2}{*}{ Mother's age } & 45.4 & 43.9 & 42.6 & 43.2 & 43.4 \\
\hline & $(5.4)$ & $(10.2)$ & $(4.8)$ & $(10.6)$ & $(5.3)$ \\
\hline Mother born before 1945 & $62.8 \%$ & $50.6 \%$ & $45.6 \%$ & $36.4 \%$ & $35.6 \%$ \\
\hline Mother's education: primary & $64.0 \%$ & $58.9 \%$ & $45.5 \%$ & $21.3 \%$ & $17.3 \%$ \\
\hline Mother's education: secondary & $32.7 \%$ & $27.9 \%$ & $43.3 \%$ & $53.9 \%$ & $62.3 \%$ \\
\hline Mother's education: tertiary & $3.3 \%$ & $13.2 \%$ & $11.2 \%$ & $24.8 \%$ & $20.3 \%$ \\
\hline Mother agrees child should leave at 18 & $15.0 \%$ & $68.6 \%$ & $43.9 \%$ & $53.6 \%$ & $59.8 \%$ \\
\hline Mother is divorced \& single-parent & $2.7 \%$ & $16.9 \%$ & $13.5 \%$ & $18.0 \%$ & $5.2 \%$ \\
\hline Mother is widowed \& single-parent & $5.3 \%$ & $3.6 \%$ & $3.8 \%$ & $5.8 \%$ & $6.5 \%$ \\
\hline No siblings at home & $14.9 \%$ & $21.4 \%$ & $24.3 \%$ & $33.6 \%$ & $13.7 \%$ \\
\hline Only child & $9.6 \%$ & $8.4 \%$ & $13.5 \%$ & $19.0 \%$ & $7.0 \%$ \\
\hline Child has experienced parental divorce & $3.7 \%$ & $19.2 \%$ & $16.9 \%$ & $21.5 \%$ & $5.4 \%$ \\
\hline Child has experienced parental divorce before 18 & $2.6 \%$ & $16.2 \%$ & $12.9 \%$ & $16.7 \%$ & $5.2 \%$ \\
\hline Child has experienced parental death & $12.1 \%$ & $6.3 \%$ & $10.1 \%$ & $12.0 \%$ & $14.3 \%$ \\
\hline Child has experienced parental death before 18 & $5.2 \%$ & $3.5 \%$ & $3.7 \%$ & $5.3 \%$ & $6.5 \%$ \\
\hline Total children & 21,983 & 6,110 & 7,683 & 4,867 & 4,519 \\
\hline Total households & 10,046 & 2,601 & 4,085 & 2,878 & 2,101 \\
\hline Total year - observations & 202,507 & 31,416 & 56,792 & 32,073 & 34,813 \\
\hline
\end{tabular}

Notes: Most of descriptive statistics refer to when the child is 18 years old.

Mother's age, mother is divorced/widowed, siblings at home are time-varying variables.

As we can easily notice, the spread of marital dissolution is quite different in the contexts considered. This obviously results in different proportions of children experiencing parental divorce going from more than one out of five in Russia, to the $17 \%$ and $19 \%$ of respectively Hungary and France, to extremely low levels in Italy (less than 4\%) and Georgia (5\%). These figures are consistent with the last available official data, which report a very different total 
divorce rate ${ }^{4}$ in the countries considered: varying from very low levels of Georgia and Italy (respectively $6 \%$ and 13\%), to a high level (above 40\%) for France, Hungary and Russia. ${ }^{5}$ These numbers are higher than the percentages we find, because they refer to the synthetic cohort in 2002 (2009 for Georgia), while our sample is also includes much older women, who experienced a lower probability of getting divorced.

As for the other variables we see that mean age of the mothers when the child is 18 is very similar in all the countries, above 40, nevertheless when we look at the percentage of women born before 1945 we see that the Italian and the French samples have a larger percentage of women belonging to the older cohort than the Russian and Georgian ones, while Hungary is in the middle. This means that on average at the time of interview Italian and French women were older than women from the other countries. A reflection of this is that the mean level of education of women living in these two countries is lower compared to Hungary, Russia and Georgia, where we observe a larger percentage of women with middle and high education.

An interesting variable is the opinion of the mothers about the right time for a child to leave the parental home. Italy is really an outlier, with just $15 \%$ of the women agreeing that a young adult should start living on his or her own by the age of 18 , while in the other countries this percentage varies from $44 \%$ to $68 \%$. However this is not surprising given the trends observed in the Mediterranean countries, where adult children tend to stay longer in the parents' home compared to other European countries. There are not only the worse labor market conditions or the less generous welfare state provisions that may cause such behavior, but also a more familist and conservative way of thinking in the society.

As for family composition we see that the percentage of only children varies substantially between the countries, indeed we see relatively low percentages in Georgia, Italy and France (around 8\%), a bit higher in Hungary (around 13\%) and much higher in Russia (around 19\%).

\section{The effects of post-separation on single-motherhood}

Results of the complementary log-log models, with random effects at household level, are reported in Tables 3, 4, 5. Table 3 reports the first results, when we estimate a gross effect of being the child of divorced parents or of a widowed mother on the decision of leaving home (equations 3 and 5). Table 4 instead reports the results when we interact the divorce or widow variables with variables indicating the timing of divorce or death and the presence of siblings (equations 4 and 6). Finally, Table 5 sums up the development and co-residence effects for children of both divorced and widowed mothers, with and without siblings.

In all the models we estimate the hazard of the time of leaving home starting at the age of 18 . As a result, a positive coefficient indicates a positive effect of that variable on the hazard (i.e. a faster process of nest-leaving, thus at a younger age), whereas, obviously, a negative coefficient reflects a slower rate of nest-leaving (at older ages).

\footnotetext{
${ }^{4}$ The "total divorce rate" is the probability of divorce for a married person if he or she were to pass through his/her marriage years conforming to the duration-specific divorce rates of a given year. The rate refers to a synthetic marriage cohort. It is computed by the summation of divorce rates by duration of marriage (generally up to 30 years), observed in a given year.

${ }^{5}$ Data for Italy, France and Hungary come from the latest available Eurostat information, and for Georgia and Russia from national official statistics.
} 
The control variables have similar effects on all countries across all models; hence results are reported just in Table 3 referring to the estimation of equation 3. Moreover the signs of the coefficients are the expected ones and confirm previous research. Females leave home earlier than males and the effect is particularly large in Georgia and Hungary; obviously, older children are more at risk than younger ones to leave the home. Mother's age has a small negative effect in all countries, while mother's cohort has a positive effect, to be interpreted as children of mothers belonging to an older cohort are more at risk of leaving the home than children of mothers belonging to a younger cohort. With regard to mother's education, we observe that the higher is the education of the mother, the lower is the risk of leaving the home for children. This is probably due to the fact that children whose parents have reached a high level of education reach themselves higher education. Moreover, their families are - on average - richer, and these two facts theoretically delay the decision to leave home. An interesting variable is the one catching the opinion of the parents about the right age to leave the parental home; not surprisingly, children whose parents believe that young adults should start living on their own when they turn 18 are more at risk of leaving their parents' home.

When we look at the coefficient of the gross effect of divorce on the decision to leave home, we instead obtain different results in different countries (Table 3, coefficient $\beta_{0}$ ). Divorce has a positive effect in Italy, while it has a negative effect in Russia. The effect is not significant in the remaining countries. Therefore an analysis of the effect of being a child of divorced parents estimated with a simple dummy for divorce does not lead to any general conclusion and does not tell us what is causing certain behaviors and why we find differences between the analyzed countries.

When we do the same analysis for children of widowed mothers, instead of children of divorced parents, using equation 5 , we find that in all countries the death of the father has a negative effect on the risk of leaving home (Table 3, bottom part, coefficient $\lambda_{0}$ ). The effect is significant everywhere apart from France. The fact that we find a common pattern of the effect of death in all the countries while this is not the case for divorce could be due to the selection effect coming along with the choice of divorce. These results are shown in Table 4, which reports the effect of divorce or widowhood interacted with other variables related to the timing of the divorce or death and the presence of siblings (equations 4 and 5). All the other control variables have been included, but coefficients are not reported.

In the first line of Table 4 (coefficient $\beta_{1}$ ) we observe the effect of divorce, which - after including all the interactions - corresponds to the co-residence effect in case of the presence of siblings. The coefficients are negative and significant for all countries with the exception of Italy. In the second line (coefficient $\beta_{2}$ ) we find that having experienced divorce before age 18 accelerates the decision to leave home in France, Hungary and Russia. In the third line, results of the interaction between experiencing divorce before 18 and being the only child at home at the time of divorce are only significant, with a delaying effect, in Russia (coefficient $\beta_{3}$ ). Finally we find a negative effect of divorce when being the last child in the household in Hungary, Italy and Russia (coefficient $\beta_{4}$ ).

Results concerning the death of the father confirm a faster decision to leave home for children who experienced the death of a parent before age 18 (coefficient $\lambda_{2}$ ) in Italy, France and Hungary and a negative effect when being the last child in the household (coefficient $\lambda_{4}$ ) in all countries but Russia. Not all results are statistically significant in the estimation with parental death (Table 4, bottom part), but the significant effects are not different from the significant effects in the estimation with parental divorce (Table 4, upper part). 
Table 3: Gross effect of divorce or father's death on the hazard of a child leaving the parental home

\begin{tabular}{|c|c|c|c|c|c|}
\hline & Italy & France & Hungary & Russia & Georgia \\
\hline & \multicolumn{5}{|c|}{ PARENTAL DIVORCE } \\
\hline \multirow{2}{*}{ Child is female } & $0.537 * * *$ & $0.547 * * *$ & $0.665^{* * *}$ & $0.412 * * *$ & $1.068 * * *$ \\
\hline & $(0.022)$ & $(0.038)$ & $(0.039)$ & $(0.053)$ & $(0.065)$ \\
\hline \multirow{2}{*}{ Child's age } & $0.638 * * *$ & $0.587 * * *$ & $0.737 * * *$ & $0.249 * * *$ & $0.227 * * *$ \\
\hline & $(0.016)$ & $(0.036)$ & $(0.033)$ & $(0.041)$ & $(0.037)$ \\
\hline \multirow{2}{*}{ Child's age square } & $-0.009 * * *$ & $-0.009 * * *$ & $-0.012 * * *$ & $-0.004 * * *$ & $-0.003 * * *$ \\
\hline & $(0.000)$ & $(0.001)$ & $(0.001)$ & $(0.001)$ & $(0.001)$ \\
\hline \multirow{2}{*}{ Mother's age } & $-0.034 * * *$ & $-0.016 * * *$ & $-0.027 * * *$ & $-0.024 * * *$ & $-0.017 * *$ \\
\hline & $(0.002)$ & $(0.004)$ & $(0.004)$ & $(0.006)$ & $(0.007)$ \\
\hline \multirow{2}{*}{$\begin{array}{l}\text { Mother is born before } \\
1945\end{array}$} & $0.531 * * *$ & $0.112 * *$ & $0.487 * * *$ & $0.294 * * *$ & $0.579 * * *$ \\
\hline & $(0.034)$ & $(0.051)$ & $(0.048)$ & $(0.071)$ & $(0.100)$ \\
\hline \multirow{2}{*}{$\begin{array}{l}\text { Mother's education: } \\
\text { secondary }\end{array}$} & $-0.369 * * *$ & 0.012 & $-0.318 * * *$ & -0.104 & $-0.349 * * *$ \\
\hline & $(0.033)$ & $(0.056)$ & $(0.049)$ & $(0.084)$ & $(0.109)$ \\
\hline \multirow{2}{*}{$\begin{array}{l}\text { Mother's education: } \\
\text { tertiary }\end{array}$} & $-0.574 * * *$ & $0.177 * *$ & $-0.492 * * *$ & -0.107 & $-0.589 * * *$ \\
\hline & $(0.088)$ & $(0.074)$ & $(0.078)$ & $(0.065)$ & $(0.133)$ \\
\hline \multirow{2}{*}{$\begin{array}{l}\text { Mother agrees child } \\
\text { should leave at } 18\end{array}$} & $0.221 * * *$ & $0.314 * * *$ & $0.121 * * *$ & $0.174 * * *$ & -0.055 \\
\hline & $(0.039)$ & $(0.052)$ & $(0.045)$ & $(0.065)$ & $(0.081)$ \\
\hline \multirow{2}{*}{$\begin{array}{c}\text { Mother is divorced } \& \\
\text { single-parent } \\
\boldsymbol{\beta}_{0}\end{array}$} & $0.119^{*}$ & 0.026 & -0.073 & $-0.500 * * *$ & -0.200 \\
\hline & $(0.071)$ & $(0.057)$ & $(0.058)$ & $(0.073)$ & $(0.157)$ \\
\hline \multirow{2}{*}{ Constant } & $-11.414^{* * *}$ & $-9.582 * * *$ & $-11.767 * * *$ & $-4.854 * * *$ & $-6.023 * * *$ \\
\hline & $(0.223)$ & $(0.469)$ & $(0.430)$ & $(0.551)$ & $(0.532)$ \\
\hline \multirow{2}{*}{ Rho } & $0.280 * * *$ & $0.295^{* * *}$ & $0.302 * * *$ & $0.428 * * *$ & $0.401 * * *$ \\
\hline & $(0.011)$ & $(0.0189$ & $(0.018)$ & $(0.025)$ & $(0.0271)$ \\
\hline Year observations & 163,697 & 27,205 & 45,231 & 25,033 & 26,400 \\
\hline Num of households & 9,230 & 2,505 & 3,734 & 2,597 & 1,859 \\
\hline \multirow{2}{*}{$\begin{array}{c}\text { Mother is widowed } \\
\text { \& single mother } \\
\lambda_{0}\end{array}$} & $-0.102 * * *$ & -0.112 & $-0.346^{* * *}$ & $-0.444 * * *$ & $-0.180 *$ \\
\hline & $(0.036)$ & $(0.088)$ & $(0.072)$ & $(0.097)$ & $(0.095)$ \\
\hline (all controls) & $\mathrm{X}$ & $\mathrm{X}$ & $\mathrm{X}$ & $\mathrm{X}$ & $\mathrm{X}$ \\
\hline Year observations & 195,838 & 24,152 & 46,235 & 23,783 & 33,066 \\
\hline Num of households & 9,581 & 2,119 & 3,360 & 2,223 & 1,948 \\
\hline
\end{tabular}

Notes: Coefficients are reported together with standard errors in brackets (*** significant at 1\% level, ** at 5\%, $*$ at $10 \%)$. Result from likelihood ratio test for rho equal to 0 is reported $(* * *$ significant at $1 \%$ level, $* *$ at $5 \%, *$ at $1 \%$ ) 
Table 4: Divorce timing and sibling presence effects on the hazard of a child leaving the parental home

\begin{tabular}{|c|c|c|c|c|c|}
\hline & Italy & France & Hungary & Russia & Georgia \\
\hline & \multicolumn{5}{|c|}{ PARENTAL DIVORCE } \\
\hline \multirow{2}{*}{$\begin{array}{l}\text { Mother is divorced \& } \\
\text { single-parent: } \beta_{1}\end{array}$} & 0.124 & $-0.362 * * *$ & $-0.243 * *$ & $-0.570 * * *$ & $-1.535^{*}$ \\
\hline & $(0.124)$ & $(0.123)$ & $(0.116)$ & $(0.157)$ & $(0.863)$ \\
\hline \multirow{2}{*}{$\begin{array}{l}\text { Divorce experienced } \\
\text { before age } 18: \beta_{2}\end{array}$} & 0.237 & $0.636^{* * *}$ & $0.248^{* *}$ & $0.554 * * *$ & 1.362 \\
\hline & $(0.147)$ & $(0.132)$ & $(0.124)$ & $(0.168)$ & $(0.864)$ \\
\hline \multirow{2}{*}{$\begin{array}{l}\text { Divorce experienced } \\
\text { before age } 18 \& \text { only child: } \beta_{3}\end{array}$} & 0.215 & -0.143 & 0.019 & $-0.329 *$ & 0.120 \\
\hline & $(0.218)$ & $(0.162)$ & $(0.161)$ & $(0.180)$ & $(0.413)$ \\
\hline \multirow{3}{*}{$\begin{array}{l}\text { Mother is divorced, } \\
\text { single mother, and no } \\
\text { siblings in the HH: } \beta_{4}\end{array}$} & $-0.433 * * *$ & $-0.212 * *$ & -0.044 & $-0.469 * * *$ & 0.012 \\
\hline & $(0.142)$ & $(0.094)$ & $(0.105)$ & $(0.136$ & $(0.324)$ \\
\hline & \multicolumn{5}{|c|}{ PARENTAL DEATH } \\
\hline \multirow{2}{*}{$\begin{array}{l}\text { Mother is widowed \& } \\
\text { single mother: } \lambda_{1}\end{array}$} & -0.005 & -0.181 & $-0.239 * *$ & $-0.284^{*}$ & 0.084 \\
\hline & $(0.054)$ & $(0.142)$ & $(0.112)$ & $(0.159)$ & $(0.138)$ \\
\hline \multirow{2}{*}{$\begin{array}{l}\text { Death experienced } \\
\text { before age } 18: \lambda_{2}\end{array}$} & $0.161^{* *}$ & $0.674 * * *$ & $0.443 * * *$ & 0.169 & -0.088 \\
\hline & $(0.067)$ & $(0.166)$ & $(0.443)$ & $(0.189)$ & $(0.182)$ \\
\hline \multirow{2}{*}{$\begin{array}{l}\text { Death experienced } \\
\text { before age } 18 \& \text { only child: } \lambda_{3}\end{array}$} & 0.115 & 0.058 & $-0.653 * *$ & $-0.998 * * *$ & $1.240 * * *$ \\
\hline & $(0.156)$ & $(0.470)$ & $(0.333)$ & $(0.353)$ & $(0.375)$ \\
\hline \multirow{2}{*}{$\begin{array}{l}\text { Mother is widowed, } \\
\text { single mother, and no } \\
\text { siblings in the HH: } \lambda_{4}\end{array}$} & $-0.382 * * *$ & $-0.058 * * *$ & $-0.447 * * *$ & -0.234 & $-0.790^{* * *}$ \\
\hline & $(0.064)$ & $(0.470)$ & $(0.132)$ & $(0.180)$ & $(0.184)$ \\
\hline
\end{tabular}

Notes: Coefficients are reported together with standard errors in brackets (*** significant at $1 \%$ level, $* *$ at $5 \%$,

* at $10 \%)$. HH stands for Household.

To comment in more depth, we pass to Table 5, in which we summarize the results for equation 6. In this table we report the coefficients for the development and co-residence effects for children with and without siblings.

The development effect of divorce is positive in all countries, accelerating the process of leaving home. In particular it is significant for only children in Italy, France and Georgia $\left(\beta_{2}+\right.$ $\beta_{3}$ ), while it is significant for children who have siblings in France, Hungary and Russia $\left(\beta_{2}\right)$. This result confirms previous studies that already find that children of divorced parents tend to leave home earlier. Possible reasons explained by this development effect could be that they tend enter into union at younger ages and hence set up a new household; or they usually study fewer years than children coming from stable families, which makes them enter into the labour market at younger ages and gain economic independence earlier (which allows them to leave by themselves); or they may be less attached to their parents, due to a harder parentchild relationship faced during childhood, after divorce.

We cannot say much about the role of siblings in this case: the difference in the development effect (as estimated by $\beta_{3}$ in Table 4) is never significant. The positive development effect seems to be driven by "only" children in Italy and Georgia, while by "more" children in France, Hungary, and Russia. However, the difference in the effects due to the presence or absence of siblings seems more due to the low power of the estimator (due to a small sample size and low variability) than to a substantial argument. In both cases (with or without siblings), the development effect is positive and the coefficients are larger than the corresponding standard errors. Hence divorce influences the development of children during childhood and makes them grow up differently from children with parents in stable unions. 
Table 5: Development and co-residence effects on the hazard of a child leaving the parental home

\begin{tabular}{|c|c|c|c|c|c|}
\hline & Italy & France & Hungary & Russia & Georgia \\
\hline & \multicolumn{5}{|c|}{ PARENTAL DIVORCE } \\
\hline \multirow{2}{*}{ Gross effect: $\beta_{0}$} & $0.119^{*}$ & 0.026 & -0.073 & $-0.500 * * *$ & -0.200 \\
\hline & $(0.071)$ & $(0.057)$ & $(0.058)$ & $(0.073)$ & $(0.157)$ \\
\hline \multirow{2}{*}{$\begin{array}{l}\text { Development effect, } \\
\text { only child: } \beta_{2}+\beta_{3}\end{array}$} & $0.452 * *$ & $0.493 * *$ & 0.267 & 0.225 & $1.482 *$ \\
\hline & $(0.226)$ & $(0.191)$ & $(0.178)$ & $(0.205)$ & $(0.859)$ \\
\hline \multirow{2}{*}{$\begin{array}{l}\text { Development effect, } \\
\text { more children: } \beta_{2}\end{array}$} & 0.237 & $0.636^{* * *}$ & $0.248^{* *}$ & $0.554 * * *$ & 1.362 \\
\hline & $(0.147)$ & $(0.132)$ & $(0.123)$ & $(0.168)$ & $(0.860)$ \\
\hline \multirow{2}{*}{$\begin{array}{l}\text { Co-residence effect, } \\
\text { last child in the } \mathrm{HH} \text { : } \\
\beta_{1}+\beta_{4}\end{array}$} & $-0.310^{* *}$ & $-0.575^{* * *}$ & $-0.287^{* *}$ & $-1.039 * * *$ & $-1.523^{*}$ \\
\hline & $(0.151)$ & $(0.137)$ & $(0.126)$ & $(0.165)$ & $(0.816)$ \\
\hline \multirow{3}{*}{$\begin{array}{l}\text { Co-residence effect, } \\
\text { siblings in the HH: } \beta_{1}\end{array}$} & 0.124 & $-0.362 * * *$ & $-0.243 * *$ & $-0.570 * * *$ & $-1.535^{*}$ \\
\hline & $(0.124)$ & $(0.123)$ & $(0.116)$ & $(0.157)$ & $(0.863)$ \\
\hline & \multicolumn{5}{|c|}{ PARENTAL DEATH } \\
\hline \multirow{2}{*}{ Gross effect: $\lambda_{0}$} & $-0.102 * * *$ & -0.112 & $-0.346^{* * *}$ & $-0.444 * * *$ & $-0.180 *$ \\
\hline & $(0.036)$ & $(0.088)$ & $(0.072)$ & $(0.097)$ & $(0.095)$ \\
\hline \multirow{2}{*}{$\begin{array}{l}\text { Development effect, } \\
\text { only child: } \lambda_{2}+\lambda_{3}\end{array}$} & $0.275^{*}$ & 0.732 & -0.210 & $-0.828 * *$ & $1.153^{* * *}$ \\
\hline & $(0.153)$ & $(0.471)$ & $(0.323)$ & $(0.335)$ & $(0.362)$ \\
\hline \multirow{2}{*}{$\begin{array}{l}\text { Development effect, } \\
\text { more children: } \lambda_{2}\end{array}$} & $0.161^{* *}$ & $0.674)$ & $0.443 * * *$ & 0.169 & -0.087 \\
\hline & $(0.069)$ & $(0.470)$ & $(0.140)$ & $(0.189)$ & $(0.182)$ \\
\hline \multirow{2}{*}{$\begin{array}{l}\text { Co-residence effect, } \\
\text { last child in the HH: } \\
\lambda_{1}+\lambda_{4}\end{array}$} & $-0.387 * * *$ & $-0.751 * * *$ & $-0.706^{* * *}$ & $-0.518 * * *$ & $-0.710^{* * *}$ \\
\hline & $(0.059)$ & $(0.151)$ & $(0.113)$ & $(0.150)$ & $(0.172)$ \\
\hline \multirow{2}{*}{$\begin{array}{l}\text { Co-residence effect, } \\
\text { siblings in the HH: } \lambda_{1}\end{array}$} & -0.005 & -0.181 & $-0.239 * *$ & $-0.284 *$ & 0.084 \\
\hline & $(0.054)$ & $(0.142)$ & $(0.112)$ & $(0.160)$ & $(0.138)$ \\
\hline
\end{tabular}

Notes: Coefficients are reported together with standard errors in brackets $(* * *$ significant at $1 \%$ level, $* *$ at $5 \%$,

* at $10 \%)$. HH stands for Household.

The co-residence effect is negative in all the countries especially for the last child in the household $\left(\beta_{1}+\beta_{4}\right)$. The effect is always significant. This suggests that at the time a child can decide whether to leave the parental home, being the last one in the home with a lone mother delays the departure, probably for fear of leaving the mother alone and/or for the fact that the home is not so crowded and there is enough privacy. This fact, from a different point of view, confirms Rainer and Siedler's (2009) results, which find that only children tend to live closer to their parents, compared to children who have siblings, and that, among families with more than one child, youngest siblings (i.e., the last one who leaves the parental home) tend to live closer to their parents than older siblings. Only children or children who are the last to leave the parental home, are more concerned about their parents (their single mother, in our case) and behave differently compared to children who do have siblings still living at home. The co-residence effect is negative and significant in all countries except for Italy, also for children who co-reside with siblings in the household $\left(\beta_{1}\right)$; nevertheless the magnitude of the coefficients is smaller. This could suggest that the absence of the father, even in the presence of other siblings, contributes to making the home less crowded and therefore without strong incentives to leave. 
We now turn to the results concerning the death of the father. When looking at the same coefficients estimated for the children of married/widowed mothers we find the same strong negative co-residence effect $\left(\lambda_{1}+\lambda_{4}\right.$ and $\left.\lambda_{1}\right)$. Results are larger for the last child in the household, stressing the "care of the mother" argument more than the "privacy" argument. The development effect is positive and significant for children who had other siblings in the home at the time of death in Italy and Hungary $\left(\lambda_{2}\right)$. It is positive for only children in Georgia and Italy $\left(\lambda_{2}+\lambda_{3}\right)$.

Given that the coefficients obtained with the widow specification are relatively similar to the ones obtained with divorce, we think that the selection effect is not very important in our topic. Once the divorce event is netted off by the identification of the co-residence and development effects, which are helpful in understanding through which channels and at which point in time divorce can have an impact on the leaving home decision, cross-country differences disappear. Indeed if we stopped at the gross effect of divorce we would find controversial results in different countries, while when we separate this effect considering the co-residence and development effects we find much more similar results in all the countries, meaning that the pure gross effect it is not enough to explain the dynamics through which divorce influences a child's behavior.

\section{Conclusion, discussion and open issues}

We have looked more closely the relationship between childhood family structure and young adults' nest-leaving process. Our attempt to disentangle different effects of parental divorce on the timing of the children's home-leaving confirms the hypothesis that the simple association between divorce and the process of transition to adulthood can mask different effects, which can have opposite and contradictory effects on the timing of leaving home.

The "gross divorce effect" on leaving home differs in sign and significance across countries. In contrast, we obtain consistent and significant results across all countries for what we called the "development effect" and the "co-residence effect". For the first effect, it is known in the literature that family disruption during childhood has a negative effect on children's human capital development and cognitive and non-cognitive skill formation, and this in turn, affects the timing of leaving home significantly accelerating the process. For the second effect, however, our findings show that children living with a lone mother leave the home at a slower rate.

The general conclusion is that parental family histories have to be taken into great consideration when the demographic behavior of young people is analyzed. The different effects emerging from our study can help to understand the leaving home process. From previous research the effect of family disruption has always been found as decreasing the age at nest-leaving, whereas here we sustain that this is a gross composition of different components, and that the specific effect of post-divorce family arrangement and structure cannot be neglected.

From a policy point of view, the results can also contribute to predicting how increasing divorce rates may affect the time young people decide to leave parental home. This step of transition to adulthood is highly context-dependent, related to welfare measures, such as specific measures for youth autonomy but also to the welfare of disruptive family, i.e. the economical help to poor lone mothers. Furthermore, also the post-divorce behavior of separated parents plays an important role for children, in particular the propensity of re- 
partnering. In certain contexts - such as the Italian one - where the age at leaving home is relatively high and, at the same time, divorce is spreading at a rapid pace, but the rate of repartnering of divorced mothers is quite low, the event of divorce can result in a further postponement of nest-leaving by the divorced mother's children. This will be particularly true for those who are a lone child or the last child at home, without cohabiting siblings. Further research should focus on identifying what mechanisms may explain the positive development effect and negative co-residence effect: whether children of divorce parents leave earlier the parental home because they are studying less, forming a partnership earlier, looking earlier for independency because of a more conflict family environment; and the reasons why the last child in the household is refrained from leaving. In order to do this, we would need better retrospective data on schooling, work, family formation, and attitudes of children.

\section{Acknowledgements}

Funding from the ERC for the CODEC project (Stg 201194), P.I. Arnstein Aassve, is gratefully acknowledged.

\section{References}

Aassve, A., Betti, G., Mazzuco, S.and Mencarini, L. (2007). "Marital disruption and economic well-being: a comparative analysis", Journal of the Royal Statistical Society Series A (Statistics in Society), 170(3): 781-799

Aassve, A., Betti, G., Mazzuco, S. and Mencarini, L. (2009). "Marital disruption and economic well-being: Poverty, income and lifestyle deprivation", in: Hans-Jürgen Andreß \& Dina Hummelsheim (eds.) When Marriage Ends: Economic and Social Consequences of Partnership Dissolution, Edward Elgar Publishing, UK.

Amato, P.R. and Booth, A. (1991). "The Consequences of Divorce for Attitudes Toward Divorce and Gender Roles.” Journal of Family Issues 12:306-322

Amato, P.R. and DeBoer, D.D. (2001). "The Transmission of Marital Instability across Generations: Relationship Skills or Commitment to Marriage?", Journal of Marriage and the Family, 63(4):1038-1051

Amato, P.R., Spencer Loomis, L. and Booth, A. (1995). "Parental divorce, marital conflict, and offspring well-being during early adulthood", Social Force, 73(3): 895-915

Aquilino, W.S. (1991). "Family structure and home-leaving: a further specification of the relationship", Journal of Marriage and the Family, 53(4): 999-1010

Aquilino, W. S. (1994). "Impact of childhood family disruption on young adults' relationships with parents", Journal of Marriage and the Family, 56(2):295-313

Axinn, W. and Thornton, A. (1996). "The influence of parents' marital dissolutions on children's attitudes toward family formation", Demography, 33(1): 66-81

Astone, N.M. and McLanahan, S. (1994). "Family structure, residential mobility, and school dropout: a research note", Demography, 31(4): 575-584

Aughinbaugh, A.A., Pierret, C.R. and Rothstein, D.S. (2005). "The impact of family structure transitions on youth achievement: evidence from the children of the NLSY79", Demography, 42(3):447-468

Bernhardt, E., Gahaler, M., Goldscheider, F. (2005) "Childhood family structure and routes out of parental home in Sweden", Acta Sociologica, 48 (2): 99-115

Billari, F.C. and Liefbroer, A. (2010). "Towards a new pattern of transition to adulthood?", Advances in Life Course Research, 15(2-3): 59-75 
Billari, F.C., Philipov, D., Baizan, P. (2001) "Leaving home in Europe. The experience of cohorts born around 1960", International Journal of Population Geography, 7(5) 339356

Booth, A. and P.R. Amato (1994). "Parental Marital Quality, Parental Divorce, and Relations With Parents", Journal of Marriage and the Family 56:21-34

Cherlin, A.J., Furstenberg, F.F., Chase-Lansdale, P.L., Kiernan, K.E., Robins, P.K., Morrison, D.R. and Teitler, J.O. (1991). "Longitudinal studies of effects of divorce on children in Great Britain and the United States", Science, 252(5011): 1386-1389

Cherlin, A.J., Kiernan, E.K. and Chase-Lansdale, P.L. (1995). "Parental divorce in childhood and demographic outcomes in young adulthood", Demography, 32(3):299-318

Corijn, M. and Klijzing, E. (eds). (2001). "Transitions to adulthood in Europe", European Association for Population Studies. Dordrecht: Kluwer

Cummings, M.E. and Davies, P.T. (1994). "Children and marital conflict: the impact of family dispute and resolution", Guilford Series on Social and Emotional Development.

Furstenberg, F.F. and Teitler, J.O. (1994). "Reconsidering the effects of marital disruption: what happens to children of divorce in early adulthood?", Journal of Family Issues, 15(2): 173-190

Goldscheider, F.K. and Goldscheider, C. (1998). "The effects of childhood family structure on leaving and returning home", Journal of Marriage and the Family, 60(3): 745-56

Goldscheider, F.K. and Goldscheider, C. (1989). "Family structure and conflict: nest leaving expectations of young adults and their parents", Journal of Marriage and the Family, 51(1): 87-97

Goldscheider, F.K. and Goldscheider, C. (1999). "The changing transition to adulthood. leaving and returning home", Thousand Oaks, CA: Sage

Holdsworth, C. (2000). "Leaving home in Britain and Spain", European Sociological Review, 16(2): 201-222

Jenkins, S.P. (2005). "Survival analysis". Unpublished manuscript, Institute for Social and Economic Research, University of Essex, Colchester, UK

Kiernan, K. (1997). "The legacy of parental divorce: social, economic and demographic experiences in adulthood", LSE STICERD Research Paper no. CASE001

McLanahan, S. (1985), "Family structure and the reproduction of poverty", American Journal of Sociology, 90(4): 873-901

McLanahan, S. (1988). "Family structure and dependency: early transitions to female household headship", Demography, 25(1): 1-16

McLanahan, S. and Bumpass, L. (1988), "Intergenerational consequences of family disruption", American Journal of Sociology, 94(1): 130-152

McLanahan, S., and Garfinkel, I. (1989). "Single mothers, the underclass, and social policy", Annals of the American Academy of Political and Social Science, 501(1): 92-104

McLanahan, S. and Percheski, C. (2008). "Family structure and the reproduction of inequalities", Annual Review of Sociology, 34: 257-276

McLanahan, S. and Sandefur, G.D. (1994). "Growing up with a single parent: what hurts, what helps", Cambridge: Harvard University Press.

Mitchell, B. (1994). "Family structure and leaving the nest: a social resource perspective", Sociological Perspectives, 37(4), 651-671

Musick, K. and Bumpass, L. (1999). "How do prior experiences in the family affect transition to adulthood?" in Alan Booth, Ann C. Crouter, and Michael J. Shanahan (Eds.), Transitions to Adulthood in a Changing Economy: No Work, No Family, No Future?, Praeger Publisher, Westport US, 69-102 
O’Connor, T.G., Thorpe, K., Dunn, J., and Golding, J. (2003). "Parental divorce and adjustment in adulthood: findings from a community sample", Journal of Child Psychology and Psychiatry, 40(5): 777-789

Ongaro, F. and Mazzuco, S. (2009). "Parental separation and family formation: evidence from Italy", Advances in Life Course Research, 14(3): 119-130

Rainer, H. and Siedler, T. (2009). "O brother, where art thou? The effects of having a sibling on geographic mobility and labor market outcomes", Economica, 76(303):528-556

Steele, F., Sigle-Rushton, W., and Kravdal, O. (2009). "Consequences of family disruption on children's educational outcomes in Norway”, Demography, 46(3): 553-574

Tang, S. (1997). "The timing of home leaving: a comparison of early, on-time, and late home leavers", Journal of Youth and Adolescence, 26 (1): 13-23

Teachman, J. (2002). "Childhood Living Arrangements and the Intergenerational Transmission of Divorce", Journal of Marriage and Family, 64(3): 717-729.

Thornton, A. (1991). "Influence of the Marital History of Parents on the Marital and Cohabitational Experience of Children”, American Journal of Sociology, 96(4): 86894. 